Dhaka University J. Biol. Sci. 28(2): 211-218, 2019 (July)

\title{
DETERMINING INITIAL PSYCHOMETRIC PROPERTIES OF PARENTING SENSE OF COMPETENCE SCALE IN THE CONTEXT OF BANGLADESH
}

\author{
Nafiza Ferdowshi* and Niger Sultana \\ Department of Educational and Counselling Psychology, University of Dhaka, \\ Dhaka-1000, Bangladesh
}

Key words: Parent satisfaction, Parent efficacy, Parenting

\begin{abstract}
The purposes of the present study were to translate the Parenting Sense of Competence (PSOC) scale and to determine its initial psychometric properties. Three hundred mothers were selected as participants from Dhaka city who have children aged 6 to 10 years. Collected data were analyzed to determine psychometrics by using Cronbach alpha, Spearman-Brown's split-half and exploratory factor analysis. Results showed that internal consistencies were: Cronbach $\alpha=0.663$ and split-half reliability $r=0.636$. As both internal consistencies value were quite similar that would make PSOC scale's reliability more supportive. Initially validity was conducted on pilot basis by measuring content validity and construct validity $(r=0.628, p<0.01)$. Study limitations and further implications were also discussed.
\end{abstract}

\section{Introduction}

Motherhood is a time of celebration, welcoming new born. It is also time of psychological stress that can cause adaptation challenge for a mother ${ }^{(1)}$. Some women cope with the tasks of mother and are satisfied with their role. However, the mothers who cannot cope due to stressful demands perceive themselves as incompetent mothers ${ }^{(2-3)}$. Alternatively, there are some mothers who show maternal competency that indicate their secure attachment with their children, less problem behavior in their children, and expression of more positive emotions towards children ${ }^{(4)}$. Evidence also suggests a relationship between maternal incompetency and maternal depression which influences the quality of parenting and, ultimately, cognitive and psychosocial development of the children ${ }^{(5-7)}$. In line with this, parenting self-efficacy and parenting satisfaction is strongly correlated for the overall outcome of child development ${ }^{(8-10)}$. For example, the mothers who are satisfied with their role have harmonious parenting style and complaint less child behavior problem ${ }^{(11)}$. A cross-cultural study has been conducted with 500 low income parents coming from diverse ethnic background. This study reports that parental competence is strongly associated with parenting practice across all ethnic

*Author for correspondence: <nf.bidhu@gmail.com>. 
groups ${ }^{(12)}$. Therefore, a large body of research indicates parenting self-efficacy as an important factor that reduces risk factors like maternal depression and child temperament(13-14). Furthermore, another study has speculated that maternal feelings of competence likely to be fostered by infants who are manageable and signal their needs effectively ${ }^{(15)}$. By contrast, low maternal self-efficacy might be expected when mothers must cope with the infants who are continuously irritable, and face difficulty in reading ${ }^{(16)}$. Without the feeling of self-efficacy to fulfill the maternal role leads to depression. Thus, the mothers who have lower competence level of maternal role were expected to have a lower level of self-esteem and more depression ${ }^{(17)}$.

Literature review has revealed that the PSOC is one of the most commonly used tools for measuring parental competency(18). Originally this scale developed by GibaudWallston and Wandersman in 1978 with two sub-scales: Skill/knowledge (assess the degree to which parent required the skill to be good parent) and value/comfort (assess the degree to which the parent values parenthood and feel comfortable)(19). This scale further adapted in 1989 by Johnston and Mash. They renamed the previous value/comfort subscale as 'satisfaction' and skill/knowledge subscale as 'efficacy'. The researchers used Canadian normative sample of 297 mothers and 215 fathers of 4-9 years old children. The PSOC total score was determined by summing 16 items that loaded two factors, the final item (item no. 17) of the scale is omitted as it did not load on any factor in the analysis. As a result, two factor structure of parental satisfaction and parental efficacy became this scale more popular to use. Findings indicated acceptable level of internal consistencies, that was $\alpha=0.79$ for the total scale, $\alpha=0.75$ for satisfaction, and $\alpha=$ 0.76 for efficacy sub-scale ${ }^{(20)}$.

The PSOC scale has been adapted across various cultural contexts, such as China, Australia, Thailand, and Portuguese. Gilmore and Cuskelly (2008) have provided further evidence of validity by using a larger Australian normative sample of 1201 parents (586 mothers and 615 fathers) of infants and children under the age of 18 years. In this research, they used PSOC's 17 items and found four sub-scales, that is: 'Satisfaction', 'efficacy', 'interest' and 'control'. Internal consistencies of subscales were $\alpha=0.72$ (mothers) and $\alpha=0.76$ (fathers) for satisfaction, $\alpha=0.68$ (mothers) and $\alpha=0.74$ (fathers) for efficacy, $\alpha=0.62$ (mothers) and $\alpha=0.57$ (fathers) for interest; however, the researchers did not include the control sub-scale due to inadequate alpha value, that is, $\alpha=0.44$ for mothers and $\alpha=0.57$ for fathers(21). Besides this, the PSOC has been translated into Chinese in 2007 with 170 mothers of postnatal period. The researchers found internal consistency $\alpha=0.85$ for the total scale where $\alpha=0.80$ and $\alpha=0.77$, respectively for the subscale 'efficacy' and 'satisfaction'(22). After that, the scale was tested with 195 fathers to be fathers in Thailand where the results showed high internal consistencies: 0.78 for the total scale and 0.73 and 0.83 , respectively for the skill/knowledge and valuing/comfort subscale ${ }^{(23)}$. In Portuguese, the researchers used 16-item 6-point Likert type PSOC scale 
with 146 mothers of children aged 18 or more than 18 years. They found $\alpha=0.69$ and $\alpha=$ 0.65 , respectively for the efficacy and satisfaction sub-scale(24).

As evidence revealed that measuring parental competence considers an important outcome. Researchers found a significant relationship of parental self-esteem in positive parenting and child development ${ }^{(22)}$. In a Bangladeshi study, the researchers showed that paternal and maternal rejection had significant negative correlation with self-esteem and life satisfaction(25). Though this local study measured parenting self-esteem, they used general self-esteem scale; however, it was not specifically designed for measuring selfesteem with parents. In line with this, the rationale of this current study underlies on the growing demands of parenting-based researches in the context of Bangladesh. The changing nature of family, focusing on early childhood development, and increasing importance of parenting intervention are the main reasons of such research interests. Though parenting competence is an important construct for evaluating the research outcomes, there is a scarcity of available tools for directly measuring parental competency. This study attempts to overcome such shortcoming of using parental competency scale in Bangladeshi context.

The aims of this study were to translate the PSOC, to evaluate the PSOC for crosscultural equivalency, and to examine the initial psychometric properties for using it with Bangladeshi mothers.

\section{Materials and Methods}

A total of 300 mothers of children aged 6 - 10 years were conveniently taken as participants in this study. Participants were taken from three different schools in which two schools from North and one school from South Dhaka City Corporation. All three schools followed Bangla medium, English medium and English version as their way of teaching method. In this study, participants were recruited from both privileged and underprivileged conditions. Privileged participants $(n=270)$ were indicated school teachers and school guardians who had target aged children. In addition, female cleaners, office peons and security guards were considered as underprivileged mothers $(n=30)$ of this study.

The Parenting Sense of Competence Scale (PSOC), developed by Gibaud-Wallston in 1978. The PSOC is a 17 item, 6-point Likert scale, with 2 subscales: Efficacy and satisfaction that scored ranging from $1=$ strongly disagree to $6=$ strongly agree. The efficacy sub-scale consisted of 8 items $(1,6,7,10,13,15$ and 17) and the satisfaction subscale contained 9 items $(2,3,4,5,8,9,12,14$ and 16). Here, items 2, 3, 4, 5, 8, 9, 12, 14 and 16 were coded reverse. The higher the score, the higher the parenting sense of competence indicated.

The translation and adaptation of parenting sense of competence scale included several stages which are being described step by step ${ }^{(26)}$. 
At first, two independent translators translated English PSOC scale into Bangla where the authors of this study played the role of translators.

After that, for checking the two independent translated version of the PSOC scale, the research team was formed by including three research students and the supervisor of this study. The research team then checked the language and meaning of the content.

Then, three experts were given the scale to give their feedback and comments. Their comments were compared and then incorporated into the Bangla version of the scale.

Next, two female persons were selected to conduct back translation of the Bangla PSOC. One of the back translators was the editor in a daily English newspaper and another was a renowned public university graduate from the background of Psychology and having research orientation. Both translators formed two versions of English PSOC scale. For judging the equivalence of these two back translated versions of PSOC, the research team approached one of the researchers who involved in PSOC adaptation in Australia, from English speaking background, and faculty at Queensland University of Technology. She compared two back translated PSOC with the original English version and found discrepancies with 3 items of the scale, that is, item no. 1, 13, and 14. Then, the researchers and supervisor compared the Bangla version with foreign expert's comments about 3 items of the scale. As a result, the research team reworded those 3 items and finalized the Bangla version of PSOC for piloting.

Afterward, pilot-testing of Bangla translated PSOC was conducted with conveniently selected 20 mothers. On this pilot phase, the researchers used internal consistency which value was $\alpha=0.61$ for PSOC total, $\alpha=0.51$ for satisfaction, and $\alpha=0.50$ for efficacy subscale. In addition, the researchers used pearson product moment correlation analysis for measuring test-retest reliability (pre-test with one-week interval of post-test) that was found for total scale $r=0.98$, for satisfaction $r=0.99$, and for efficacy sub-scale $r=0.96$. Furthermore, content validity was checked by the expert panels during the translation of the scale. In addition, construct validity was measured by correlating Bangla adapted Rosenberg Self-Esteem (RSE) scale with Bangla PSOC scale, that found significant correlation $\mathrm{r}=0.628, \mathrm{p}<0.01$. This positive and significant correlation between PSOC and RSE showed supporting the construct validity of the PSOC. This finding was not surprising and supported the previous findings of parents with low self-efficacy tend to report more negative reactions to difficult child behavior ${ }^{(27)}$.

By considering the feedback from the pilot study, the Bangla version of PSOC was finalized. The final Bangla PSOC was given to 300 participants for testing initial psychometric properties, that is, reliability, item analysis, and factor analysis.

For conducting the final Bangla PSOC, the authors were taken ethical approval from the Ethics Committee of the Department of Educational and Counselling Psychology, University of Dhaka. The questionnaire was administered individually. Rapport was established before administering the questionnaire. Questionnaire was provided with 
necessary information and they were allowed to ask any question regarding the questionnaire. Confidentiality was informed to the participants. It took $20-25$ minutes time on an average for the privileged participants, and 30 - 35 minutes for the underprivileged participants. After that, participant were thanked for their participation in the study. The duration of the total data collection was 6 months that included pilot and main field data. For fulfilling required sample, $36 \%$ more people were given the questionnaire.

\section{Results and Discussion}

The main objective of the present study was to adapt Parenting Sense of Competence Scale into Bangla for the use of Bangladeshi women who are being mother. To adapt the PSOC scale in Bangladesh, this study used exploratory factor analysis, internal consistencies, and item analysis. Results were discussed on the basis of objectives that reported here (Table 1$)$.

Table 1. Reliability coefficients of the Bangla version of PSOC scale.

\begin{tabular}{lcc}
\hline Scale & $\begin{array}{c}\text { Cronbach's Alpha } \\
(\mathrm{N}=300)\end{array}$ & $\begin{array}{c}\text { Split-half } \\
(\mathrm{N}=300)\end{array}$ \\
\hline PSOC total & 0.663 & 0.636 \\
Parental satisfaction & 0.595 & 0.642 \\
Parental efficacy & 0.668 & 0.626 \\
\hline
\end{tabular}

The reliability of Bangla PSOC was calculated by two process: Cronbach alpha and Spearman-Brown's split half method. The internal consistency of adapted Bangla PSOC total was $\alpha=0.0663$; the internal consistencies for 'satisfaction' and for 'efficacy' sub-scale were $\alpha=0.595$ and $\alpha=0.668$, respectively. This study finding supported the Portuguese PSOC adaptation study though that study used PSOC scale with 16-item 6 point Likert format ${ }^{(24)}$. In addition, Australian adaptation findings ${ }^{(21)}$ also partially supported with this study result, that is, similar alpha value for mothers 'efficacy' subs-scale $(\alpha=0.68)$. Other previous studies showed higher value for internal consistency that did not support by this study ${ }^{(22-23)}$. The reason for the variation is result were such as cultural differences, educational status of the participants, socio-economic background, scope and/or opportunity (Table 2).

Here, 3 items showed greater internal consistency than total scale internal consistency. If the researchers omit these items internal consistency slightly increases that was $\alpha=0.69$. May be 14 item can be used in future study but used 17 items in this study.

Exploratory Factor Analysis (EFA) was used to identify the factor structure of PSOC scale. We calculated this analysis in some stages. In the first stage we calculated 
adequacy of sample by Kaiser-Meyer-Olkin $(\mathrm{KMO})$ measure and found $\mathrm{KMO}=0.629 ; \chi^{2}$ $=1011.721, \mathrm{df}=136(\mathrm{p}<0.001)$ Bartlett's test of sphericity. The KMO measured the sampling adequacy (which determines if the responses given with the sample are adequate or not). For measuring the strength of the relationship of variables, Bartlett's test value indicated its significance and provides a reasonable basis for factor analysis. As the original PSOC scale had two factors, this analysis with fixed number of factors (2) also extracted 2 factors that labeled as 'satisfaction' for 1st factor and 'efficacy' for 2 nd factor (Table 3).

Table 2. PSOC item total statistics.

\begin{tabular}{cccc}
\hline $\begin{array}{c}\text { PSOC } \\
\text { item }\end{array}$ & $\begin{array}{c}\text { Scale mean if item } \\
\text { deleted }\end{array}$ & $\begin{array}{c}\text { Scale variance if } \\
\text { item deleted }\end{array}$ & $\begin{array}{c}\text { Cronbach's Alpha if } \\
\text { item deleted }\end{array}$ \\
\hline 1 & 63.5233 & 118.504 & 0.670 \\
2 & 64.0567 & 106.923 & 0.646 \\
3 & 65.8333 & 110.494 & 0.656 \\
4 & 65.0433 & 107.252 & 0.649 \\
5 & 65.0400 & 104.253 & 0.642 \\
6 & 63.9867 & 110.903 & 0.653 \\
7 & 64.1233 & 107.078 & 0.641 \\
8 & 64.4500 & 105.660 & 0.641 \\
9 & 65.9367 & 109.297 & 0.649 \\
10 & 64.5467 & 102.643 & 0.624 \\
11 & 63.3267 & 113.980 & 0.654 \\
12 & 64.0567 & 105.278 & 0.632 \\
13 & 63.9267 & 106.570 & 0.639 \\
14 & 64.8933 & 114.851 & 0.679 \\
15 & 64.1267 & 103.047 & 0.625 \\
16 & 66.3867 & 112.158 & 0.655 \\
17 & 63.0100 & 119.181 & 0.667 \\
\hline
\end{tabular}

Table 3. Extracted factors, corresponding items and factors loading ranges of Parenting Sense of Competence Section.

\begin{tabular}{lll}
\hline Factors & Items & Factor loading range \\
\hline 1 & $1,2,3,5,8,9,14,16$ & $0.003-0.204$ \\
2 & $4,6,7,10,11,12,13,15,17$ & $0.019-0.447$ \\
\hline
\end{tabular}


From Table 3 the result of the initial analysis revealed 2 factors loading statistics. Factor loadings for factor 1 ranged from 0.003 to 0.204 , for factor 2 the factor loading ranged from 0.019 - 0.447. Item no 1, 4, 7 and 12 did not match with the original factors for cultural differences. For example, the statement of item no. 4 is "I do not know why it is but sometimes when I am supposed to be in control, I feel more like the one being manipulated". In original scale, this item is in satisfaction sub-scale. But in our cultural context this statement is more suitable as efficacy or skill not as satisfaction.

The current study bears some limitations. At first, the convenience sampling selection procedure of participant and sample size do not necessarily represent the population. We used a little amount of underprivileged sample; it could be increased more for representing the population. Validity was not tested for final study so further validation measuring is necessary.

\section{References}

1. Tulman L and J Fawcett 2003. Women's health during and after pregnancy: A theory-based study of adaptation to change. New York: Springer.

2. Horowitz JA and EG Damato 1999. Mothers' perceptions of postpartum stress and satisfaction. Journal of Obstetric, Gynecologic and Neonatal Nursing 28(6): 595-605.

3. Leung S, DG Arthur and I Martinson 2005. Stress in women with postpartum depression: A phenomenological study. Journal of Advanced Nursing 51(4): 353-360.

4. Lovejoy MC, MR Verda, and CE Hays 1997. Convergent and discriminant validity of measures of parenting efficacy and control. Journal of Clinical Child Psychology 26(4): 366-376.

5. Luoma I, T Tamminen, P Kaukonen, P Laippala, K Puura, R Salmelin and F Almqvist 2001. Longitudinal study of maternal depressive symptoms and child well-being. Journal of the American Academy of Child and Adolescent Psychiatry 40(12):1367-1374.

6. Rogers H and J Matthews 2004. The parenting sense of competence scale: Investigation of the factor structure, reliability and validity for an Australian sample. Australian Psychologist, 39(1): 88-96.

7. Sanders MR and ML Woolley 2005. The relationship between maternal self-efficacy and parenting practices : Implications for parent training. Child: Care, Health and Development 31(1): 65-73.

8. Coleman PK and KH Karraker 1998. Self-efficacy and parenting quality: Findings and future applications. Developmental Review 18(1): 47-85.

9. Shumow L and R Lomax 2002. Parental self-efficacy: Predictor of parenting behaviour adolescent outcomes. Parenting, Science and Practice 2: 127-150.

10. Jones TL and RJ Prinz 2005. Potential roles of parental self-efficacy in parent and child adjustment: A review. Clinical Psychology Review 25: 341-363.

11. Ohan, JL, DW Leung and C Johnston 2000. The parenting sense of competence scale: Evidence of a stable factor structure and validity. Canadian Journal of Behavioral Science 32: 251-261. 
12. Teti DM and DM Gelfand 1991. Behavioral competence among mothers of infants in the first year: The mediational role of maternal self-efficacy. Child Development 62: 918-929.

13. MacPhee D, J Fritz and J Miller-Heyl 1996. Ethnic variations in personal social networks and parenting. Child Development 67: 3278-3295.

14. Gondoli DM and SB Silverberg 1997. Maternal emotional distress and diminished responsiveness: The mediating role of parenting efficacy and parental perspective taking. Developmental Psychology 33: 861-868.

15. Goldberg S 1977. Social competence in infancy: A model of parent-infant interaction. MerrillPalmer Quarterly 23: 163-17.

16. Cutrona CE and BR Troutman 1986. Social support, infant temperament, and parenting selfefficacy: A mediational model of postpartum depression. Child Development 57: 1507-1518.

17. Bandura A 1997. Self-efficacy: The exercise of control. New York: Freeman.

18. Jones TLand RJ Prinz 2005. Potential roles of parental self-efficacy in parent and child adjustment: a review. Clinical Psychology Review 25: 341-363.

19. Gibaud-Wallston J and LP Wandersman 1978. Development and utility of the Parenting Sense of Competence scale. Paper presented at the meeting of the American Psychological Association, Toronto, Canada.

20. Johnston C and EJ Mash 1989. A measure of parenting satisfaction and efficacy. Journal of Clinical Child Psychology 18(2): 167-175.

21. Gilmore L and M Cuskelly 2008. Factor structure of the parenting sense of competence scale using a normative sample. Child: Care, Health and Development 35(1): 48-55.

22. Ngai FW, SWC Chan and E Holroyd 2007. Translation and validation of a Chinese version of the parenting sense of competence scale in Chinese mothers. Nursing Research 56 (5): 348354.doi: 10.1097 01.NNR.0000289499 .99542.94.

23. Suwansujarid T, P Vatanasomboon, N Gaylord and PLapvongwatana 2013. Validation of the parenting sense of competence scale in fathers: Thai version. Southeast Asian Journal of Tropical Medicine and Public Health 44(5): 916-926.

24. Nunes C, L Jiménez, S Menéndez, L Ayala-Nunes and V Hidalgo 2016. Psychometric properties of an adapted version of the parental sense of competence (PSOC) scale for Portuguese at-risk parents. Child and Family Social Work 21: 433-441. https://doi.org/ $10.1111 /$ cfs.12159.

25. Yasmin S and A Hossain 2014. Relation of parental rejection with self-esteem and life satisfaction of young adults. Dhaka Univ. J. Biol. Sci. 23(1): 69-76.

26. Sousa VD and W Rojjanasrirat 2011. Translation, adaptation and validation of instruments or scales for use in cross-cultural health care research: A clear and user-friendly guideline. Journal of Evaluation in Clinical Practice 17: 268-274. doi:10.1111 h.1365-2753.2010.01434.x.

27. Johnston $\mathrm{C}$ and $\mathrm{R}$ Patenaude 1994. Parent attributions for inattentive-overactive and oppositional-defiant child behaviors. Cognitive Therapy and Research 18: 261-275. 